\title{
Frequent Hard Physical Activity Lowered Serum $\beta$-Carotene Level in a Population Study of a Rural City of Japan
}

\author{
Naoyoshi Takatsuka, Norito Kawakami, Atsuko \\ Ohwaki*, Yoshinori Ito $\dagger$, Yoko Matsushita, Masayo \\ IDo and Hiroyuki SHimizu \\ Department of Public Health, Gifu University School of \\ Medicine, Gifu 500, *Department of Home Economics, \\ Nagoya Seirei Junior College, Aichi 489, and Department \\ of Public Health, Fujita Health University School of \\ Health Sciences, Aichi 470-11
}

Takatsuka, N., Kawakami, N., Ohwaki, A., Ito, Y., Matsushita, Y., Ido, M. and Shimizu, H. Frequent Hard Physical Activity Lowered Serum $\beta$-Carotene Level in a Population Study of a Rural City of Japan. Tohoku J. Exp. Med., 1995, 176 (3), 131-135 — To determine the effect of physical activity on serum $\beta$-carotene, we analyzed data about life styles including 3-day food records and blood samples collected from 57 men and 74 women in a rural city of Japan. Physical activity was asked as mean frequency of hard physical activities per week last year. A declining trend in serum $\beta$-carotene was observed with increasing frequency of hard physical activities in men. In multiple regression analyses, the frequency of hard physical activities showed a negative partial correlation coefficient $(\mathrm{r}=-0.38, p=0.007)$ with serum $\beta$-carotene in men when controlled by age, BMI (body mass index), dietary factors (carotene intake, alcohol consumption and vitamin supplements use), smoking status, serum total cholesterol and serum triglycerides. These results suggest that frequent hard physical activity decreases serum $\beta$-carotene especially in men.— exercise; $\beta$-carotene; population study

It has been reported that free radicals consume $\beta$-carotene (Burton and Ingold 1984). It is also found that physical activities increase free radicals and subsequent lipid peroxidation in human as well as experimental animals (Dillard et al. 1978; Davies et al. 1982). Singh (1992) suggested that antioxidants including $\beta$-carotene may protect against damages caused by free radical production promoted by exercise. However few reports have clarified the relationship between physical activity and antioxidants in human (Rokitzki et al. 1989; Kanter et al. 1993). In this study we investigated the relationship between

Received December 19, 1994; revision accepted for publication April 3, 1995.

Address for reprints: Naoyoshi Takatsuka, Department of Public Health, Gifu University School of Medicine, 40 Tsukasa-machi, Gifu 500, Japan. 
frequency of hard physical activities and serum $\beta$-carotene levels among samples from a cohort who were residents in a rural city of Japan.

\section{Materials And Methods}

Six hundred persons were randomly selected from 36,990 residents aged 35 years and over in a rural city of Gifu prefecture, Japan. A recruiting mail was sent to each subject in May, 1992, and 192 persons whose occupations were various agreed to join the study. We collected information on their food consumption by 3-day food records and their physical activities by self administered questionnaire in summer, 1992. After excluding 51 persons with no information on at least one item and 10 persons with a history of cancer, we analyzed the data from 57 men $($ mean age $=57.8 ;$ s.D. $=10.8)$ and 74 women (mean age $=54.6 ;$ s.D. $=10.5)$. We also collected their blood samples at the same time.

The blood samples were centrifuged within $3 \mathrm{hr}$ after the collection and the separated sera were stored at $-80^{\circ} \mathrm{C}$ for one year. The concentrations of carotenoids of the sera were measured by high-performance liquid chromatography (Ito et al. 1987).

Frequency of hard physical activities was assessed by a single-item question: "How many times a week did you take part in vigorous physical activity (strenuous sports or work) long enough to work up a sweat last year ?" (Siconolfi et al. 1985). This question was not restrict to specific works and sports. The subjects were classified into 4 groups according to each quartile of the frequency in the total subjects. In multiple regression analyses, the following scores were assigned to the frequency categories: none $=0$; once $=1 ; 2-3$ times $=2.5 ; 4$ times and over $=5.5$.

The dietitians in our group indicated the subjects how to record 3-day records at their first visit in summer, 1992. Three days after the first visit, they visited the subjects again and checked each miswriting and supplemented the missing answers by interview. Nutrients intakes for each subject were calculated based on Japan Food Composition Tables, 4th edition (1982). Other variables were collected from the questionnaire: age (coded as: $<55$ years old $=0, \geq 55$ years old $=1)$, body mass index $(\mathrm{BMI})\left(\mathrm{kg} / \mathrm{m}^{2}\right)$, smoking status (coded as: never or ex-smoker $=0$; current smoker $=1$ ), mean alcohol consumption per day in the last year (coded as: $0 \mathrm{~g} /$ day pure ethanol $=0,>0 \mathrm{~g} /$ day pure ethanol $=1$ ), vitamin supplements use (4 times and over/week user of some kinds of vitamin supplements $=1$; others $=0$ ), serum total cholesterol and serum triglycerides which were assayed by enzyme method.

In statistical analysis, Kruskal-Wallis test and Spearman correlation coefficients were employed. And the multiple linear regression analyses of the common log-transformed values of serum $\beta$-carotene on variables described above were performed by sex. Since some previous studies had evaluated the variables of age, BMI, carotene intake, smoking status, alcohol consumption, vitamin 
supplements use, serum total cholesterol and serum triglycerides as the influential factors on serum $\beta$-carotene (Roidt et al. 1988; Stryker et al. 1988), we also included them. Common log-transformed value was used for the variable of carotene intake and serum triglycerides, because it showed skew deviation. The analyses were carried out on a PC with the computer program of SAS Ver. 6.04 (1988).

\section{RESULTS}

A slightly declining trend of serum $\beta$-carotene concentrations was observed with increase in frequency of hard physical activities in men (Table 1), but the difference was not statistically significant. Rank correlation coefficients between serum $\beta$-carotene levels and frequency of hard physical activities were $-0.15(p=$ $0.28)$ in men and $0.07(p=0.53)$ in women, respectively. The multiple regression analyses indicated significant negative partial correlation coefficient between serum $\beta$-carotene levels and frequency of hard physical activities when controlled by the other potential confounding factors among men (Table 2).

\section{Discussion}

We found a significant negative partial correlation between serum $\beta$-carotene levels and frequency of hard physical activities in men. The findings observed in this study suggest that frequent hard physical activities reduce serum $\beta$-carotene levels.

Our results are inconsistent with a previous study (Siconolfi et al. 1985), which failed to show a significant difference in serum fat soluble vitamins including $\beta$-carotene between athletes (marathon runners, swimmers and etc.) and non athletes. There were some problems in the previous study. First, they did not use subjects representative of a community. Second, they did not control other factors like carotene intake, serum cholesterol, smoking and alcohol consumptions, which may affect serum $\beta$-carotene levels. In addition, they did not measure the

TABLE 1. Serum $\beta$-carotene concentrations by frequency of hard physical activities $^{a, b}$

\begin{tabular}{ccccc}
\hline \multirow{2}{*}{$\begin{array}{c}\text { Frequency of physical } \\
\text { activities (times/week) }\end{array}$} & $n$ & $\mu$ mol/liter & $n$ & \multicolumn{2}{c}{ Wowen } \\
\cline { 2 - 5 } & 10 & $0.44(0.17-2.47)$ & 25 & $0.96(0.13-4.75)$ \\
0 & 12 & $0.46(0.05-2.51)$ & 22 & $1.14(0.33-2.97)$ \\
1 & 14 & $0.40(0.09-1.68)$ & 20 & $1.15(0.58-3.10)$ \\
$2-3$ & 21 & $0.32(0.03-1.96)$ & 7 & $1.04(0.41-2.70)$ \\
$\geq 4$ & &
\end{tabular}

${ }^{a}$ Values are $n$ (number of persons) and median, (minimum-maximum) of serum $\beta$-carotene.

${ }^{\text {b}}$ There were no significant differences of serum $\beta$-carotene level between classes of frequency of hard physical activities in both sexes. 
TABLE 2. Predictors of serum $\beta$-carotene* concentrations in multiple regression analyses by sex

\begin{tabular}{|c|c|c|c|c|}
\hline \multirow[b]{2}{*}{ Variables } & \multicolumn{2}{|c|}{$\operatorname{Men}(n=57)$} & \multicolumn{2}{|c|}{ Women $(n=74)$} \\
\hline & $\begin{array}{l}\text { Partial correlation } \\
\text { coefficient }(\mathrm{r})\end{array}$ & $p$ & $\begin{array}{l}\text { Partial correlation } \\
\text { coefficient }(\mathrm{r})\end{array}$ & $p$ \\
\hline $\begin{array}{l}\text { Hard physical activities } \\
(\text { (times/week) })^{\mathrm{a}}\end{array}$ & -0.38 & 0.007 & 0.002 & 0.985 \\
\hline $\mathrm{Age}^{\mathrm{b}}$ & -0.05 & 0.722 & 0.02 & 0.881 \\
\hline Body mass index $\left(\mathrm{kg} / \mathrm{m}^{2}\right)$ & -0.07 & 0.640 & -0.21 & 0.084 \\
\hline Carotene intake $(\mu \mathrm{g} / \text { day })^{*}$ & 0.23 & 0.119 & 0.53 & 0.0001 \\
\hline Smoking $^{c}$ & -0.51 & 0.0002 & -0.02 & 0.899 \\
\hline Alcohold $^{\mathrm{d}}$ & -0.25 & 0.080 & 0.09 & 0.449 \\
\hline Vitamin supplements ${ }^{\mathrm{e}}$ & 0.22 & 0.130 & 0.08 & 0.526 \\
\hline $\begin{array}{l}\text { Serum total cholesterol } \\
\qquad(\mathrm{mmol} / \text { liter })\end{array}$ & 0.42 & 0.003 & 0.29 & 0.017 \\
\hline $\begin{array}{l}\text { Serum triglycerides } \\
(\mathrm{mmol} / \text { liter })^{*}\end{array}$ & -0.43 & 0.002 & -0.04 & 0.734 \\
\hline
\end{tabular}

Adjusted $\mathrm{R}^{2}=0.48$ in men

0.29 in women

${ }^{*}$ Common log-transformed values for serum $\beta$-carotene, carotene intake and serum triglycerides were included.

${ }^{a}$ none $=0$, once $=1,2-3$ times $=2.5,4$ times and over $=5.5$.

${ }^{\mathrm{b}}<55$ years old $=0, \geq 55$ years old $=1$.

${ }^{c}$ Never or ex-smoker $=0$, current smoker $=1$.

${ }^{\mathrm{d}} 0 \mathrm{~g} /$ day pure ethanol $=0,>0 \mathrm{~g} /$ day pure ethanol $=1$.

${ }^{\mathrm{e}} 4$ times and over/week user of some kinds of vitamin supplements $=1$, others $=0$.

levels of physical activity. Although our findings were based on the average values in the previous year only, we found that limited intensity of physical activities indicated by frequency of strenuous sports or work reduce serum $\beta$-carotene levels.

We failed to find the trend in women as we did in men. The difference may be due to lower frequency of hard physical activities in women and also information on physical activities which we used in this study. The length or intensity of women's physical activity may not be so long or strong even if they reported to have hard physical activities. Objective assessment of physical activities should be included in future studies. It is also thought that the difference between men and women may due to the differences of food intakes except carotene intake and hormonal environment. It should be evaluated whether the other mechanisms related to sex affect the level of serum $\beta$-carotene.

Other influential factors we included in the analyses showed almost consistent partial correlation with the previous studies (Roidt et al. 1988; Stryker et al. 1988 ), so these findings support validation of this study.

Serum $\beta$-carotene may be consumed by deoxidizing free radicals which arise 
from usual hard physical activities. There is another possibility that hard physical activities inhibit absorption of $\beta$-carotene from digestive tract. Indicators of peroxidation caused by free radicals should be measured (Lovlin et al. 1987) to clarify the mechanism which reduces $\beta$-carotene among persons with frequent hard physical activities.

\section{Acknowledgments}

This study was supported by the co-operative research on cancer, the Ministry of Education, Science and Culture of Japan (05151030).

\section{References}

1) Burton, G.W. \& Ingold, K.U. (1984) Beta carotene: An usual type of lipid antioxidant. Science, 224, 569-573.

2) Davies, K.J.A., Quintanilha, A.T., Brooks, G.A. \& Packer, L. (1982) Free radicals and tissue damage produced by exercise. Biochem. Biophys. Res. Commun., 107, 1198-1205.

3) Dillard, C.J., Litov, R.E., Savin, W.M., Dumelin, E.E. \& Tappel, A.L. (1978) Effects of exercise, vitamin $\mathrm{E}$ and ozone on pulmonary function and lipid peroxidation. $J$. Appl. Physiol., 45, 927-32.

4) Ito, Y., Sasaki, R., Minohara, M., Otani, M. \& Aoki, K. (1987) Quantitation of serum carotenoid concentrations in healthy inhabitants by high-performance liquid chromatography. Clin. Chim. Acta, 169, 197-208.

5) Japan Food Composition Tables, 4th edition (1982) The Science and Technology Agency.

6) Kanter, M.M., Nolte, L.A. \& Holloszy, J.O. (1993) Effect of an antioxidant vitamin mixture on lipid peroxidation at rest and postexercise. J. Appl. Physiol., 74, 965-969.

7) Lovlin, R., Cottle, W., Pyke, I., Kavanagh, M. \& Belcastro, A.N. (1987) Are indices of free radical damage related to exercise intensity. Eur. J. Appl. Physiol., 56, 313316.

8) Roidt, L., White, E., Goodman, G.E., Wahl, P.W., Omenn, G.S., Rollins, B. \& Karkeck, J.M. (1988) Association of food frequency questionnaire estimates of vitamin A intake with serum vitamin A levels. Am. J. Epidemiol., 128, 645-654.

9) Rokitzki, L., Berg, A. \& Keul, L. (1989) Blood and serum status of water- and fat-soluble vitamins in athletes and non-athletes. Int. J. Vitam. Nutr. Res., Suppl., 30, 192-197.

10) SAS/STAT User's Guide Version 6.04 (1988) SAS Institute, Cary, NC.

11) Siconolfi, S.F., Lasater, T. M., Snow, R.C.K. \& Carleton, R.A. (1985) Self-reported physical activity compared with maximal oxygen uptake. Am. J. Epidemiol., 112, 101-105.

12) Singh, V.N. (1992) A current perspective on nutrition and exercise. J. Nutr., 122, Suppl., 760-765.

13) Stryker, W.S., Kaplan, L.A., Stein, E.A., Stampfer, M.J., Sober, A. \& Willett, W.C. (1988) The relation of diet, cigarette smoking, and alcohol consumption to plasma beta-carotene and alpha-tocopherol levels. Am. J. Epidemiol., 127, 283-296. 